\title{
THE TAKAOKA RESPIRATOR FOR AUTOMATIC VENTILATION OF THE LUNGS
}

\author{
Allen B. Dobkin, M.D. *
}

THE NUMBer of anaesthetists who prefer to use their own hands rather than an automatic device for augmenting pulmonary ventilation for a patient during general anaesthesia is still considerable. Even those who frequently have to provide anaesthesia with controlled ventilation for very long operative procedures, or when they have several other important tasks to perform simultaneously, persist in avoiding automatic ventilators. The reasons for this have been reiterated on many occasions. An important reason is the complex meehanics of these respirators, which makes individual adjustments awkward or cumbersome and raises the fear of breakdown at a critical point during the anaesthetic procedure. Even those who have used the more recently designed respirators feel that, although freeing of their hands, relief from mental and physical fatigue, and other advantages provided by such devices have helped them to improve the care to their anaesthetized patients, some of these respirators are not easy to adjust quickly and many require more attention than it is safe to direct away from immediate observation of the patient and the operation., ${ }^{1,2.3}$

During the past ten years, a simple automatic respirator has been developed and is being used in many parts of South America. This device was designed and made by Dr. Kentaro Takaoka. He is an engineer and an anaesthetist who practices and teaches anaesthesia in Sao Paulo, Brazil. Several anaesthetists who have visited Dr. Takaoka from North America and Europe have been given one of his respirators for clinical trial, and have found that it is easy to use in clinical practice, and provides adequate pulmonary ventilation with minimal adjustments, once attached to a source of gas (directly or through a machine) and to the patient's airway. It causes little or no distraction from the immediate attention to the patient, and requires practically no maintenance.

The Takaoka respirator is compact and weighs only $400 \mathrm{gm}$. The mechanism is enc'osed in a circular aluminum case which is $8 \mathrm{~cm}$. in diameter and $3 \mathrm{~cm}$. thick. The valves to adjust pressure sensitivity (internal regulator) and cycling rate (external regulator) jut out $2.5 \mathrm{~cm}$. from the centre of the top. The expiratory vents, safety valve and the connector for the endotracheal tube jut out off-centre from the bottom. The gas inlet projects $3 \mathrm{~cm}$. from the side and has a, lateral nipple for sampling the gas (for $\mathrm{CO}_{2}$ analysis) during respiration. Figure 1 shows the intact respirator and a vertical section which are two-thirds actual size.

The respirator cycles automatically when gas is delivered from a piped supply or from any anaesthetic gas machine if the reduced pressure exceeds approximately $10 \mathrm{lb} . / \mathrm{sq}$. in. and the gas at the outlet enters a semi-distensible space. In Canadian and American hospitals the piped air, oxygen and nitrous oxide

- From the Department of Anesthesiology, Upstate Medical Center, Syracuse, New York.

Can. Anaes. Soc. J., vol. 8, no. 6, November, 1961 


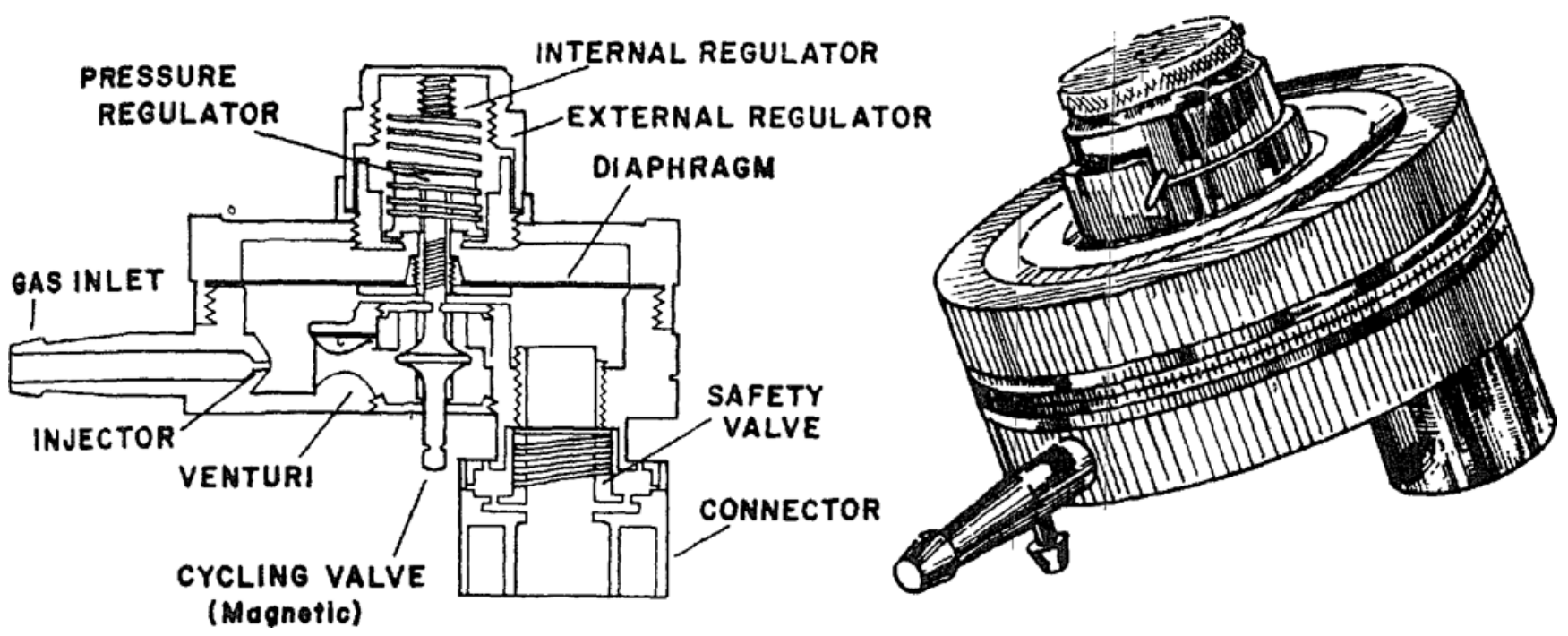

Figure 1. Diagram of the Takaoka Respirator.

supply are usually delivered at a pressure of at least $30 \mathrm{lb} . / \mathrm{sq}$. in. and on most anaesthetic machines the oxygen and nitrous oxide pressure from the tank is reduced to between 40 and $50 \mathrm{lb} . / \mathrm{sq}$. in., so that there should be no difficulty in operating the respirator on account of the pressure of the gas supply.

Earlier models of this respirator were discontinued because the duration of inspiration was too long ( 65 per cent of the cycling time). In the present model, the inspiratory positive pressure phase is equal to the expiratory phase. All expired gas is vented to the atmosphere so that no rebreathing is possible. The respirator is economical to operate because the gas which provides the motive power for inflation enters the lungs. Fresh gas enters the injector continuously from the reducing valve and flow meter. The gas supply constitutes a constantflow generator in parallel with the respirator, the effect of which is limited to the inspiratory phase. The gas is added to the lungs during inspiration and the same volume is withdrawn from the lungs during expiration. The mechanism of the respirator acts as a pressure generator with negligible series resistance. The flow of anaesthetic gas into or out of the patient is determined by the magnitude of the pressure and the compliance of the patient's lungs and is not influenced directly by the fresh gas flow. The peak pressure in the endotracheal tube during inspiration depends on the physical characteristics of the lungs and thorax and on the rate of gas flow. By adjusting the gas inflow, the peak pressure in the endotracheal tube varies between approximately 8 and $30 \mathrm{~mm}$. Hg. During clinical anaesthesia in adults it is usually between 12 and $20 \mathrm{~mm}$. Hg. when the tidal volume has been adjusted to between 300 and $750 \mathrm{ml}$. These limits can be extended briefly if necessary by holding the cycling valve in the "in" or "out" position, but this manoeuvre should not be used unless the chest is open, and the lnngs are under direct vision. A constant peak of subatmospheric pressure of 3 to $4 \mathrm{~mm}$. $\mathrm{Hg}$. occurs at the end of expiration and cannot be increased. A characteristic saw-tooth shaped flow curve is produced over the clinical range of cycling rates (Fig. 2) which differs from that produced by the Bennett Assistor, Emerson Controller-Assister and Stephenson Controlled Respiration unit only in that there is no pause at ambient pressure. However, 
the subatmospheric pressure that occurs at the termination of expiration is sufficient to reduce the mean airway pressure ( 3 to $7 \mathrm{~mm}$. Hg.). This level is similar to that found with presently available intermittent positive pressure ventilators on which expiration time has been adjusted to approximately twice the inspiration time. ${ }^{4}$

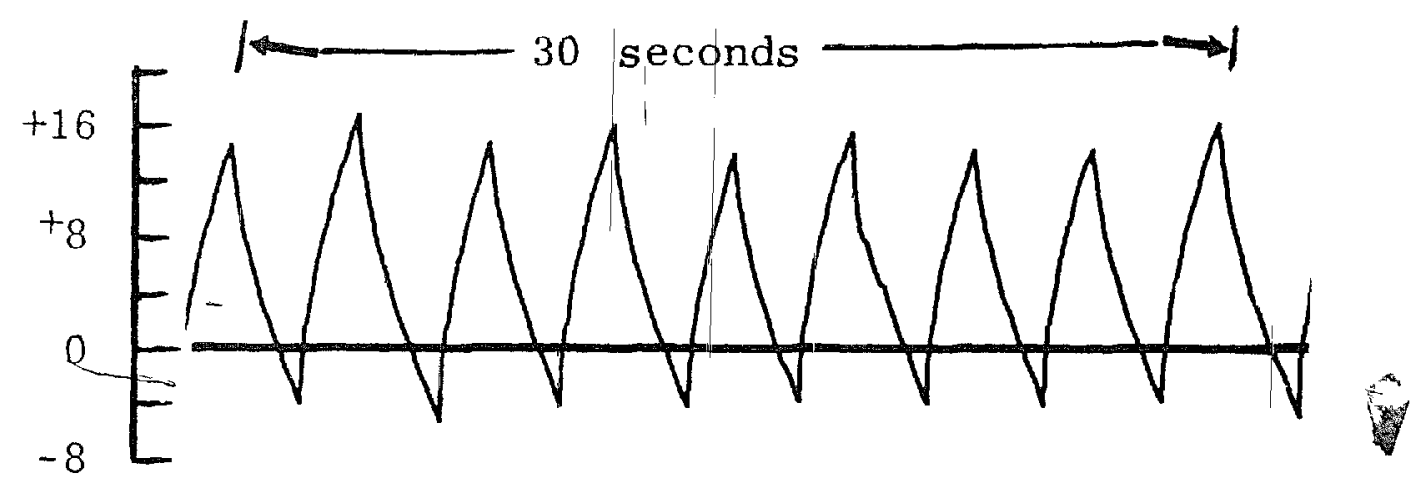

FIGURE 2. Saw-tooth pressure pattern of Takaoka Respirator (cycling rate $17 / \mathrm{min}$., paper speed $18 \mathrm{~cm} . / \mathrm{min}$.)

The rate of cycling can be adjusted by/ rotating the external regulator so that any rate between approximately 10 to 40 per minute is usually possible. By regulating the gas inflow rate, the tidal volume delivered to the endotracheal tube can be adjusted over a range which is sufficient for clinical use in adults as well as in children.

In order to use the Takaoka respirator during clinical anaesthesia, a nondistensible rubber tube with $5 / 16^{\prime \prime}$ bore should be employed to attach the gas supply beyond a reducing valve and flowmeter to the gas inlet of the respirator. The vaporizer for any liquid anaesthetic must of course be interposed between the flowmeter and the gas inlet. The rate of gas flow of oxygen, or oxygen with nitrous oxide or ethylene in sum should be twice the desired minute volume. For instance, if a minute volume of 7.5 litres is required for adequate ventilation of the patient, and when using a 1:2 mixture of oxygen and nitrous oxide, the flows must be set at 5 litres of oxygen and 10 litres of nitrous oxide.

The Takaoka respirator has no evident deleterious effect on the cardiac output or circulatory dynamics, in spite of the fact that the gas flow curve characteristics are such that the mean airway pressure is somewhat higher than might be desired during the expiration by those who insist that the mean airway pressure should be at or very near ambient pressure. However; if one compares the saw-tooth curve produced by this respirator with the "ideal curve" (type 3) described by Cournand and his associates, one finds that there is no appreciable difference, except in the shorter period of expiration. ${ }^{5}$ A negative pressure phase in the cycle removes some of the objection to the shorter expiration time. ${ }^{5,6,7,8,9,10}$ Virtue has reported that in dogs with normal blood volume and those with hypovolemia, the effect of the new model of this respirator on cardiac output is no different from that produced by manual control of respiration. ${ }^{11}$ In a series of experiments in which I studied several potent anaesthetics in dogs and in humans, no alterations in cardiovascular dynamics could be attributed to the respirator. Pulmonary ventilation was also adequate according to clinical signs 
and from data derived from analyses of anaerobic arterial blood samples to determine anion-cation balance. ${ }^{12,13,14,15}$

During the past two years the new model of the Takaoka respirator has been used during more than 400 major (abdominal and thoracic). operative procedures in humans. Pulmonary ventilation was controlled for more than a sum of 1,200 hours in these patients. In addition, the same respirator was used in experiments on more than 160 dogs in which pulmonary ventilation was controlled for more than a sum of 750 hours. It was also used on several patients who required controlled pulmonary ventilation for several days. The anaesthetics used included chloroform, halothane, halothane-ether azeotrope, methoxyflurane, trichlorethylene and trifluroethyl vinyl ether with oxygen or with nitrous oxide-oxygen. In no case of clinical or experimental use was it found necessary to remove the Takaoka respirator on account of any mechanical defect or because any patient or dog was not receiving adequate pulmonary ventilation. Although it was expected that the internal rubber diaphragm of the respirator would deteriorate under the influence of long exposures to halogenated hydrocarbons, no such effect has yet been obseved.

While the respirator was employed during clinical or experimental anaesthetics, only two adjustments were required for proper application: regulation of the rate of gas flow through the respirator, to provide adequate minute volume, and regulation of the cycling rate to provide a suitable tidal volume. If the clinician wishes to be sure that the ventilation provided is adequate, measuring devices such as the Ohio minute volume meter or the Wright respirometer may be interposed between the Takaoka respirator and the endotracheal tube. ${ }^{12}$

If anaesthesia becomes too light or when there is insufficient muscle relaxation, the cycling rhythm or rate changes. If no further administration of relaxants is desired, the rate can be reduced so that ao greater tidal volume is provided, and apnoea may be maintained by hyperventilation. When it is no longer desirable to augment the patient's pulmonary ventilation, the respirator is removed from the circuit easily, and the ordinary circle, to and fro or non-rebreathing attachment of the gas machine in use can be connected in the usual way. No case of prolonged apnoea was encountered following the use of this respirator because care was taken to reduce, the depth of anaesthesia and the use of muscle relaxants towards the end of the procedure. There were no deaths during surgery nor were there any immediate postoperative anaesthetic deaths among the anaesthetized patients on whom the Takaoka respirator was used.

This report does not imply that any of the clinical anaesthetics in which the Takaoka respirator was used could not have been administered with satisfactory results if manual artificial ventilation had been used. However, there is no doubt in the author's mind that the use of this respirator added much to the facility of managing the anaesthetic for most of the procedures in which it was considered necessary or mandatory to control the patient's pulmonary ventilation. The very simple operation of the respirator added to the peace of mind one desires when employing a mechanical aid. Many anaesthetists believe that "automatic ventilators have come to stay"; ${ }^{9}$ I feel that the Takaoka respirator is a very useful aid to the anaesthetist who works alone and often administers anaesthetics for long operations. 


\section{RÉSUMÉ}

Durant les deux dernières années, nous avons employé chez des humains, au cours de plus de 400 opérations majeures, abdominale ou thoracique, le nouveau modèle de respirateur Takaoka. La ventilation pulmonaire, chez ces malades, a été contrôlée durant plus de 1200 heures. De plus, nous avons employé le même respirateur au cours d'expériences sur plus de 160 chiens, chez qui nous avons contrôlé la ventilation pulmonaire durant plus de 750 heures. Nous avons également employé ce respirateur chez plusieurs malades exigeant une ventilation pulmonaire contrôlée durant plusieurs jours. Au cours des anesthésies, les agents employés ont été: le chloroforme, l'halothane, l'halothane-éther azéotrope, le méthoxyflurane, le trichloréthylène et le trifluoréthyl vinyl éther avec oxygène au protoxyde d'azote et oxygène. En aucune circonstance, clinique ou expérîtítentale, nous avons dî enlever le respirateur Takaoka à cause d'un trouble mécanique ou parce que le malade ou le chien n'avait pas une ventilation pulmonaire adéquate. En dépit du fait que nous nous attendions que le diaphragme caoutchouté interne ne résisterait pas à l'action prolongée des hydrocarbones halogénés auxquels il était exposé, nous n'avons pas encore observé de dommages.

\section{REFERENCES}

1. Cullen, S. C.; Comroe, J. H., Jr.; Brown, E. B., JR.; Beecher, H. K.; \& Maloney, J. V., JR. Problems in Ventilation. Anesthesiology 15: 416 (1954).

2. Mф̆RCH, E. T. \& BENSON, D. W. Automatic Artificial Respiration during Anesthesia. Proc. 3rd. Cong. Scand. Soc. Anesth.: 30 (1954).

3. Dobkin, A. B. \& WYant, G. M. Anaesthesia with Controlled Positive and Negative Pressure Respiration. 2, Review of Cardiorespiratory Function and Acid Base Homeostasis. Brit. J. Anaesth. 28: 353 (1956).

4. SAKLAd, M., SAKLAD, E., \& Cox, C. V. Choice of Pressure Breathing Apparatus. Anesth, \& Analg. 38: 32 (1959).

5. Cournand, A.; Motrey, H. L.; Werko, L.; \& Richards, D. W., JR. Physiological Studies of the Effects oc Intermittent Positive Pressure Breathing on Cardiac Output in Man. Am. J. Physiol. 152: 162 (1948).

6. Maloney, J. V., Jr. \& Handford, S. W. Circulatory Responses to Intermittent Positive and Alternating Positive Negative Pressure Respiration. J. Appl. Physiol. 6: 453 (1954).

7. Dobkin, A. B.; Hubay, C. A.; Mendelsomn, H. J.; \& Hingson, R. A. Anaesthesia with Controlled Positive and Negative Rressure Respiration. 1, A Clinical Evaluation. Brit. J. Anaesth. 28: 297 (1956).

8. Dobxin, A. B. Evaluation of a Ventilator with Fixed Volume Control and Yariable Regulated Pressure. Canad. Anaes. Soc. J. 5: 288 (1958).

9. Dobkin, A. B. Regulation of Controlled Respiration: Recent Concepts Important to the Anaesthetist. Brit. J. Anaesth. 30: 282 (1958).

10. Mushin, W. W., Rendell-Baker, L., \& Thompson, P. W. Automatic Ventilation of the Lungs. Oxford: Blackwell ( 1959 ).

11. Virtue, R. W., Caranna, L. J., \& Takaoka, K. The Respiratory Pattern and Cardiac Output. Brit. J. Anaesth. 33: 77 (1961).

12. Dobkin, A. B., Johnston, H. J., \& Skinner, L. C. A Study of Chloroform in a Precision System. 1, The Effect on Anion-Cation Balance in Man. Canad. Anaes. Soc. J. 7: 257 (1960).

13. Dobkin, A. B., Skinner, L. C., \& Johnston, H. J. A Study of Chloroform Anaesthesia in a Precision System. II, The Effect on Circulatory Dynamics and Anaesthetic Morbidity. Canad. Anaes. Soc. J. 7: 379 (1960).

14. Debkin, A. B., Harland, J. H., \& Fedoruk, S. Comparison of Chloroform and Halothane on Cardio, ascular Respiratory and Metabolic Effects in Dogs. Brit. J. Anaesth. 33: $239(1961)$.

15. Dobkin, A. B. \& Fedoruk, S. Comparison of the Cardiovascular, Respiratory and Metabolic Effects of Methoxyflurane (Penthrane DA 759) and Halnthane (Fluothane) in Dogs. Anesthesiology, 22: 355 (1961). 